\title{
Efektifitas Peyuluhan Kesehatan Gigi Dan Mulut Dengan Media Video Melalui WhatsApp Dalam Meningkatkan Derajat Kesehatan Gigi Dan Mulut Di Panti Asuhan Yos Sudarso Jakarta
}

\author{
Jusuf Kristianto $^{1}$, Dwi Priharti ${ }^{1}$, Abral $^{2}$ \\ ${ }^{1}$ Politeknik Kesehatan Kemenkes Jakarta I \\ ${ }^{2}$ Politeknik Kesehatan Kemenkes Pontianak \\ Email: jusufkristianto@gmail.com
}

\begin{abstract}
Abstrak
Salah satu cara untuk meningkatkan perilaku anak dalam menjaga kesehatan gigi dan mulut adalah dengan memberikan pendidikan kesehatan gigi tentang cara menyikat gigi yang baik dan benar dengan menggunakan alat bantu atau media yang tepat dan sesuai.

Upaya promotif sebagai bagian atau cabang dari ilmu kesehatan mempunyai dua sisi yakni sisi ilmu dan seni. Sisi seni, yakni praktisi atau aplikasi promosi kesehatan, merupakan penunjang bagi program-program kesehatan lain untuk meningkatkan kemampuan masyarakat dalam memelihara dan meningkatkan kesehatannya tidak terkecuali kesehatan gigi dan mulut.

Sebagian besar penduduk menyikat gigi setiap hari saat mandi pagi atau mandi sore. Kebiasaan benar menyikat gigi penduduk Indonesia hanya 2,3\% (Riskesdas, 2013).

Metode penelitian menggunakan Quasi experiment with control group design. Penelitian dilakukan pada dua kelompok intervensi. Jumlah sampel sebanyak 30 untuk kelompok intervensi maupun kontrol. Uji statistik menggunakan dependent t-test, independent t-test.

Pada penelitian ini terlihat terjadi penurunan OHIS yang siknifikan dari 2,1 turun menjadi 1,162

Pada kelompok dengan Program menyikat gigi dan disertai pemberian penyuluhan disertai video melalui WhatsApp.

Hasil penelitian menunjukkan bahwa ada perbedaan terhadap peningkatan kebersihan gigi dan mulut antara kelompok yang diberikan intervensi WhatsApp dan kelompok yang tidak diberikan WhatsApp, di mana $p=0,001<0,05$, Hasil Penelitian menunjukkan penyuluhan
\end{abstract}

dengan demonstrasi disertai video menyikat gigi terbukti meningkatan derajat kebersihan mulut (OHIS)pada anak asuh di Yos Sudarso, Cilandak Jakarta Selatan

Disarankan kepada tenaga kesehatan gigi untuk menggunakan modifikasi penyuluhan disertai demostrasi menyikat gig dan diperkuat dengan video melalui WhatsApp agar dapat meningkatkan derajat kebersihan mulut yang pada akhirnya akan menurunkan angka kejadian gigi berlubang

Kata Kunci:

Video Interaktif WhatsApp, Peran,Pengasuh, Derajat Kebersihan Gigi dan Mulut ( OHIS )

\begin{abstract}
One way to improve your child's behavior in keeping oral health is to provide dental health education on how to brush your teeth is good and right with using tools or proper and appropriate media AIDS Promotif as part of the effort or the branch of health science has two sides i.e. side of science and art. Side of the art, i.e., the practitioner or the application of health promotion is supporting, for other health programs to improve the community in maintaining and improving health is no exception of oral health.

Most of the inhabitants of brushing your teeth every day while bathing in the morning or afternoon shower. Custom correct brushing Indonesia residents only $2.3 \%$ (Riskesdas, 2013).

The research method uses Quasi experiment with control group design. The study was conducted on two intervention groups. The
\end{abstract}


number of samples is 30 for the intervention and control groups.

Statistical test using dependent t-test, independent t-test.In this study, there was a significant decrease in OHIS from 2.1 down to 1.162In the group with a tooth brushing program and accompanied by counseling accompanied by video through WhatsApp.

The results showed that there is a difference towards improved oral hygiene among groups given by group WhatsApp interventions and not shipped WhatsApp, where $p=0.001<0.05$,

The research results with extension demonstration of brushing teeth proved to be an increase in the degree of oral hygiene (OHIS) in foster care at the Yos Sudarso Cilandak, South JakartaThe results showed that there were differences between groups and groups given with groups that were not given WhatsApp, where $\mathrm{p}=0.001<0.05$,

The results of the study showed that counseling with a demonstration with a tooth brushing video was proven to increase the degree of oral hygiene (OHIS) in foster children in Yos Sudarso, Cilandak, South Jakarta.

It is advisable to dental health personnel to use modification to tooth brushing demonstrations and reinforced with videos through Whattapps in order to improve the degree of oral hygiene which will ultimately reduce the incidence of cavities

Keywords:

WhatsApp Interactive Video , Caregiver Roles, Degree of Dental and Oral Hygiene (OHIS)

\section{Pendahuluan}

Upaya kesehatan adalah setiap kegiatan dan atau serangkaian kegiatan yang dilakukan secara terpadu, terintregasi dan berkesinambungan untuk memelihara dan meningkatkan derajat kesehatan masyarakat dalam bentuk pencegahan penyakit, peningkatan kesehatan, pengobatan penyakit, dan pemulihan kesehatan oleh pemerintah dan atau masyarakat. ${ }^{(16)}$

Hal ini sesuai dengan misi Kementerian Kesehatan Republik Indonesia 2014 yaitu melindungi kesehatan masyarakat dengan menjamin tersedianya upaya kesehatan yang paripurna, merata bermutu dan berkeadilan dengan strategi meningkatkan pelayanan kesehatan yang merata, terjangkau, bermutu dan berkeadilan, serta berbasis bukti; dengan pengutamaan pada upaya promotif dan preventif. (17)

Upaya promotif sebagai bagian atau cabang dari ilmu kesehatan, juga mempunyai dua sisi yakni sisi ilmu dan seni. Dari sisi seni, yakni praktisi atau aplikasi promosi kesehatan, merupakan penunjang bagi program-program kesehatan lain untuk meningkatkan kemampuan masyarakat dalam memelihara dan meningkatkan kesehatannya tidak terkecuali kesehatan gigi dan mulut. ${ }^{(13)}$

Kegiatan Usaha Kesehatan Gigi Sekolah (UKGS) merupakan bagian dari kegiatan Usaha Kesehatan Sekolah (UKS) yang secara rutin dilaksanakan di sekolah dengan tujuan menumbuhkan dan mewujudkan kemandirian siswa untuk hidup sehat yang memungkinkan terwujudnya derajat kesehatan masyarakat yang optimal.

Presentasi penduduk yang mempunyai masalah gigi dan mulut menurut Riskesdas tahun 2007 dan 2013 meningkat dari 23,2\% menjadi 25,9\%. Dari penduduk yang mempunyai masalah kesehatan gigi dan mulut, presentase penduduk yang menerima perawatan medis gigi meningkat dari $29,7 \%$ tahun 2007 menjadi 31,1\% pada tahun 2013. Sama halnya dengan EMD yang didefinisikan sebagai presentase penduduk yang bermasalah dengan gigi dan mulut dalam 12 bulan terakhir dikali presentase penduduk yang menerima perawatan atau pengobatan gigi dari tenaga medis gigi meningkat dari $6,9 \%$ tahu 2007 menjadi $8,1 \%$ tahun 2013. ${ }^{(15)}$

Setiap orang perlu menjaga kesehatan gigi dan mulut dengan cara menyikat gigi dengan benar untuk mencegah terjadinya karies gigi. Pertanyaan tentang perilaku menyikat gigi dalam Riskesdas 2013 bertujuan untuk mengetahui kebiasaan dan waktu menyikat gigi. Jumlah sampel untuk kelompok umur $\geq 10$ tahun berjumlah 835.256 responden. Penduduk umur $\geq 10$ tahun sebagian besar $(93,8 \%)$ menyikat gigi setiap hari. Sebagian besar penduduk juga menyikat gigi pada saat mandi sore, yaitu 
sebesar 79,7. Sebagian besar penduduk menyikat gigi setiap hari saat mandi pagi atau mandi sore. Kebiasaan benar menyikat gigi penduduk Indonesia hanya $2,3 \% .^{(1)}$

Proporsi masyarakat yang menggosok gigi setiap hari sesudah makan pagi hanya $12,6 \%$ dan sebelum tidur malam hanya $28,7 \%$. Hal ini mungkin disebabkan kurangnya pengetahuan dan kesadaran masyarakat terhadap kebersihan gigi-mulut, juga adanya wilayah yang masih sulit terjangkau informasi akibat keadaan geografi yang bervariasi. Tiga provinsi yang mempunyai presentase tertinggi dalam hal menggosok gigi adalah DKI Jakarta $(98,5 \%)$, Jawa Barat (95,8\%), dan Kalimantan Timur (95,5\%), sedangkan yang terendah di Provinsi NTT $(74,7 \%)$ dan Papua $(58,4 \%) .{ }^{(1)}$

Berdasarkan hal tersebut, maka dilakukan Pengabdian Masyarakat di Panti Asuhan Yos Sudarso Cilandak untuk dilakukan penyuluhan dan pemeriksaan kesehatangigi dan mulut pada seluruh siswa Panti Asuhan Yos Sudarso Cilandak. Faktor lainnya adalah sikap dan perilaku terhadap pemeliharaan kesehatan gigi seperti antara lain, kebersihan mulut yang berhubungan dengan frekuensi dan kebiasaan menggosok gigi, jumlah dan frekuensi makan makanan kariogenik yang menyebabkan karies $^{(2)}$.

\section{Metode}

Penelitian ini merupakan upaya untuk menciptakan metode baru dengan menggunakan Peyuluhan Kesehatan Gigi Dan Mulut Dengan Media Video Kesehatan Melalui WhatsApp untuk meningkatkan derajat kebersihan gigi dan mulut pada anak Panti Asuhan Yos Sudarso Cilandak. Penelitian ini dilaksanakan di Panti Asuhan Yos Sudarso Cilandak, Jakarta Selatan pada tahun 2017 dengan jumlah sampel sebanyak 60 orang. Kelompok pertama yaitu kelompok intervensi yang diberi pendidikan kesehatan gigi dengan demonstrasi menyikat gigi dengan alat bantu model rahang serta didampingi dengan Video WhatsApps dan kelompok kontrol diberikan pendidikan menyikat gigi dengan menggunakan alat bantú model rahang tanpa Video WhatsApp.
Sumber-sumber utama yang diperlukan dalam penelitian ini adalah: 1) sikat gigi, 2) murid, 3) pengasuh anak, dan 4) Video WhatsApp.

Pembuatan metode baru ini dilaksanakan dengan beberapa langkah: 1) promosi dengan cara demonstrasi menggosok gigi yang benar dan memberikan video melalui Media WhatsApp, 2) meningkatkan kemampuan keluarga di Panti Asuhan dalam pencegahan dini terhadap lubang gigi, 3) memantau menggosok gigi dengan Video WhatsApp, 4) metode pengujian melalui penelitian lapangan, 5) kesimpulan dan pengajuan rekomendasi.

\section{Hasil}

\section{Peranan Media Interaktif Video Melalui WhatsApp Terhadap Kebersihan Gigi Dan Mulut}

Pemilihan metode didasarkan pada teori bahwa perawatan kesehatan gigi dengan menyikat gigi menggunakan model rahang, serta pendampingan dengan menggunakan video melalui WhatsApp mempunyai hasil yang lebih baik dibanding dengan tanpa melakukan pendampingan. Peran pendamping sangat diperlukan dalam mengasuh, mendidik, mendorong dan mengawasi.Sikap pengasuh berperan penting terhadap kesehatan gigi anak dalam mendasari terbentuknya perilaku positif yang mendukung kesehatan gigi anak ${ }^{(3)}$. Pemberian video melalui WhatsApp akan membantu dalam pelaksanaan pemantauan kebiasaan menyikat gigi anak oleh guru maupun Pengasuh Panti Asuhan. Kesehatan gigi dan mulut anak tergantung pada kepatuhan anak dan pendampingan orang tua/ pengasuh panti asuhan dalam merawatnya ${ }^{(4)}$. Dengan adanya Penyuluhan dengan demotrasi dan disertai penguatan melalui video menyikat gigi melalui WhatsApp akan memberikan dampak positif berupa meningkatnya tingkat kebersihan gigi dan mulut anak yang dilihat dari penurunan Debris Index pada sasaran yang diberikan video menyikat gigi . Untuk lebih jelasnya dapat dilihat pada Tabel 1. 
Tabel 1

Distribusi Rata-rata Oral Hygiene Index (OHIS) Responden Menurut Pengukuran Pertama dan Keempat pada Panti Asuhan di Cilandak Jakarta Selatan dengan intervensi video menyikat gigi melalui WhatsApps Tahun 2017

\section{Variable \\ OHIS}

Before Intervention

After Intervention

\author{
Mean \\ 2.106 \\ 1.162
}

SD

1.034

0.622
SE

0.188

0.113

$\begin{array}{ll}\text { P Value } & \mathbf{N} \\ 0.0001 & 30\end{array}$

sikap dan Perilakunya. Perubahan perilaku dapat dibantu dengan penerapan inovasi media interaktif melalui WhatsApp yang akan memberikan cara menggosok gigi yang baik dan efisien bagi sasaran, agar menjadi lebih baik.

Sedangkan dalam jangka panjang, setelah perubahan perilaku tentu akan meningkatkan kesehatan gigi dan mulut, sehingga akan mencegah terjadinya gigi berlubang serta penurunan angka kesakitan akibat karies gigi dan gingivitis.

Penelitian ini menyajikan penggunaan media interaktif melalui video WhatsApp sebagai metode untuk meningkatkan kesehatan gigi dan mulut siswa sekolah dasar yang tinggal di Rumah atau di Panti Asuhan .

Namun disadari bahwa sebagian media penyuluhan kesehatan yang ada pada saat ini hanya menggunakan media konvensional berupa brosur, leaflet ,poster, flipchard Artinya media penyuluhan kesehatan yang digunakan oleh para penyuluh kesehatan saat ini sebagian besar belum menggunakan media dunia maya dengan memanfaatkan fasilitas website, blog, yang biasa disebut dengan media sosial. ${ }^{(18)}$

Sebagai media baru dalam berkomunikasi, media sosial merupakan sarana komunikasi yang memanfaatkan internet dan handphone (HP) yang ditopang oleh aplikasi atau software. Tidak seperti komunikasi di internet pada masa sebelumnya yang cenderung searah, komunikasi di media sosial kini bersifat interaktif, terbuka dan memungkinkan setiap orang untuk ikut berpartisipasi di dalamnya. Sehingga dimungkinkan media sosial ini akan efektif dalam rangka mempengaruhi orang baik secara individu, kelompok bahkan dalam jumlah yang banyak (massal), karena media 
sosial ini didesain untuk memudahkan interaksi sosial, yang bersifat interaktif atau dua arah. Beberapa media social yang popular dan banyak digunakan antara lain : Facebook, Twitter, Instagram, Path dan WhatsApp ${ }^{(18)}$

Pengetahuan anak dan orang tua/ pengasuh tentang kesehatan gigi dan mulut sangat penting dalam membentuk perilaku yang mendukung kebersihan gigi dan mulut anak orang tua dengan pengetahuan rendah mengenai kesehatan gigi dan mulut merupakan faktor predisposisi dari perilaku yang tidak mendukung kesehatan gigi dan mulut anak ${ }^{(8),(4)}$. Hal tersebut dapat terjadi karena orang tua/ pengasuh adalah kekuatan sosial utama yang mempengaruhi perkembangan anak, termasuk perawatan kesehatan gigi dan mulut anak ${ }^{(9),(3),(10)}$. Pengetahuan dipengaruhi oleh pendidikan, terutama promosi dan demonstrasi perawatan kebersihan gigi dan mulut. Pendidikan kesehatan adalah pendekatan yang paling sederhana dan hemat biaya $^{(11),(12)}$. Pendidikan penyuluhan berupa promosi dan demonstrasi yang dilengkapi dengan video interaktif melalui program aplikasi WhatsApp akan mempermudah anak dan orang tua/ pengasuh untuk makin mahir dalam perawatan kesehatan gigi dan mulut anak. Pendidikan kesehatan meningkatkan kesadaran akan pentingnya kesehatan gigi dan mulut ${ }^{(6)}$. Oleh karena itu adanya video interaktif melalui WhatsApp akan membantu anak dan orang tua / pengasuh untuk merawat kesehatan gigi dan mulut anak. Perhatian orang tua/ pengasuh terhadap kesehatan gigi dan mulut anak dimulai sejak kecil agar diperoleh suatu kebiasaan untuk memperoleh kesehatan secara umum.

Peran orang tua/ pengasuh mempunyai pengaruh terhadap kebersihan gigi dan mulut anak. Keluarga, yaitu, sikap orang tua/ pengasuih terhadap pentingnya kebersihan mulut, memainkan peran utama dalam pelestarian gigi anak-anak yang sehat. ${ }^{(7)}$. Hal ini dapat terjadi karena perilaku dan praktek kesehatan orang tua/ pengasuh umumnya memiliki pengaruh terhadap kesehatan gigi anak $^{(5)}$. Anak belajar melalui pengamatan mereka terhadap suatu kegiatan yang dilakukan ibu-ayah, pengasuh atau gurunya. Anak belajar dari apa yang mereka dengar dari orang tua dan pengasuh sehingga mereka memperoleh pengalaman tentang suatu kejadian ${ }^{(13)}$. Semakin aktif peranan orang tua/ pengasuh terhadap anaknya sehingga akan semakin baik pula perilaku anak. Status kesehatan gigi dipengaruhi oleh faktor perilaku kesehatan yang antara lain terdiri dari faktor pengetahuan, sikap dan tindakan. Peranan orang tua / pengasuh sangat penting dalam membimbing, memberikan pengertian, mengingatkan dan memberi teladan sehingga anak mampu mengembangkan pertumbuhan pribadinya, tanggung jawab orang tua dan perhatian penuh kasih sayang serta menyediakan fasilitas kapada anak agar anak dapat memelihara kesehatan gigi dan mulutnya. ${ }^{(14)}$.

\section{Kesimpulan}

Penelitian ini telah merekomendasikan pemberian video interaktif sebagai terobosan dalam peningkatan kebersihan gigi dan mulut pada murid Sekolah Dasar yang tinggal di Rumah maupun di Panti Asuhan Metode ini dapat digunakan dalam promosi yang diberi penyuluhan , praktek / demostrasi menyikat gigi dan disertai penyuluhan melalui video serta memberikan video cara menggosok gigi yang baik melalui media interaktif whatapp.

Pada Penelitian ini melalui pengabdian masyarakat yang berbasis pada Research ini dapat dibuktikan, telah terjadi peningkatan derajat kesehatan masyarakat, sesuai dengan Sistem Kesehatan Nasional yaitu upaya peningkatan derajat kesehatan melalui peningkatan peran serta masyarakat sebagai agen pembaharuan bidang kesehatan. Upaya PSM sejalan dengan butir SKN yaitu Pemberdayaan Masyarakat baik Perorangan, Kelompok, atau masyarakat umum di bidang kesehatan.Hasil penelitian membuktikan bahwa pemberian video interaktif melalui program WhatsApp mempunyai pengaruh terhadap peningkatan kebersihan gigi dan mulut anak.

\section{Daftar Pustaka}

1. Badan Penelitian dan Pengembangan Kesehatan Departemen Kesehatan, Republik Indonesia. Riset Kesehatan Dasar. Badan Penelitian dan 
Pengembangan Kesehatan Departemen Kesehatan, Republik Indonesia; 2007. 1-290 p.

2. Jovina TA. Pengaruh Kebiasaan Menyikat Gigi Terhadap Status Pengalaman Karies. Riskesdas 2007. :96.

3. Suci Mentari, Zuraida Usman Bany, Cut Fera Novita. Hubungan Peran Orang Tua Terhadap Indeks DMF-T Siswa Sekolah Dasar Dengan UKGS (Studi Pada SDN 20 Kecamatan Kuta Alam Kota Banda Aceh). Journal Caninus Denstistry. 2016 Nov;1(4):63-9.

4. Mahmoud K. Al-Omiri, Jor Board, Ahed M. AlWahadni, Khaled N. Saeed. Oral Health Attitudes, Knowledge, and Behavior Among School Children in North Jordan. Pubmed, Journal of Dental Education. 2006 February;70(2):179-87.

5. Almoudi MM, Hussein AS, Doss JG, Schroth RJ. Expectant Mothers' Readiness to Initiate Preventive Oral Health Care for Their Children. The Saudi Journal for Dental Research. 2016 Jul;7(2):118-26.

6. Djordjevic A. Parents' Knowledge about the Effects of Oral Hygiene, Proper Nutrition and Fluoride Prophylaxis on Oral Health in Early Childhood. Balkan Journal of Dental Medicine. 2018 Mar 1;22(1):26-31.

7. Saldūnaitè K, Bendoraitienè EA, Slabšinskienè E, Vasiliauskienė I, Andruškevičienè V, Zūbienè J. The Role of Parental Education and Socioeconomic Status in Dental Caries Prevention among Lithuanian Children. Medicina. 2014;50(3):156-61.

8. Sariningrum E. Hubungan Tingkat Pendidikan, Sikap dan Pengetahuan Orang Tua tentang Kebersihan Gigi dan Mulut Pada Anak Balita 3 - 5 Tahun dengan Tingkat Kejadian Karies di PAUD Jatipurno. 2009;2-7.

9. Bozorgmehr E, Hajizamani A, Malek Mohammadi T. Oral Health Behavior of Parents as a Predictor of Oral Health Status of Their Children. ISRN Dentistry. 2013;2013:1-5.

10. Chand S, Chand S, Dhanker K, Chaudhary A. Impact of Mothers' Oral Hygiene Knowledge and Practice on Oral Hygiene Status of Their 12-Year-Old Children: A Cross-Sectional Study. Journal of Indian Association of Public Health Dentistry. 2014;12(4):323.

11. Garbin CAS, Soares GB, Dócusse FRM, Garbin AJÍ, Arcieri RM. Oral Health Education in School: Parents' Attitudes and Prevalence of Caries in Children. Revista de Odontologia da UNESP. 2015 Oct 6;44(5):285-91.

12. Dinea SD, Domnariu CD. Evaluation of Parental Knowledge About Oral Health of A Preschool Children Population. 2017;3.

13. Soekidjo Notoatmodjo. Promosi Kesehatan dan Perilaku Kesehatan. Rineka Cipta. 2012

14. Husna A. Peran Orang Tua dan Perilaku Anak Dalam Menyikat Gigi Dengan Kejadian Karies Anak. :7. 2016

15. Infodatin, Pusat Data dan Informasi Kesehatan Kementerian Kesehatan RI, 2014

16. Undang Undang Kesehatan Republik Indonesia, 2009
17. Visi Misi Kementerian Kesehatan Republik Indonesia , 2014

18. Anshor, Sokhibul., Penggunaan Media Pembelajaran Berbasis Video Terhadap Aktivitas dan Hasil Belajar Geografi, Fakultas Keguruan dan Ilmu Pendidikan, Jurusan Pendidikan Ilmu Pengetahuan Sosial. Universitas Lampung. Hal : 2201 